\title{
Coffee and caffeine intake and risk of urinary incontinence: a meta-analysis of observational studies
}

\author{
Shenyou Sun ${ }^{1}$, Dongbin Liu ${ }^{1}$ and Ziyao Jiao ${ }^{2^{*}}$
}

\begin{abstract}
Background: Previous results from studies on the relationship between coffee/caffeine consumption and risk of urinary incontinence (UI) are inconclusive. We aim to assess this association using a meta-analysis of observational studies.

Methods: Pertinent studies were identified by searching electronic database (Embase, PubMed and Web of Science) and carefully reviewing the reference lists of pertinent articles until July 2015. Random-effects models were used to derive the summary ORs and corresponding $95 \% \mathrm{Cls}$.

Results: Seven studies (one case-control, two cohort and four cross-sectional) were included in our meta-analysis. The summary ORs for any versus non-consumption were 0.75 (95\% Cl 0.54-1.04) for coffee and 1.29 (95\% Cl 0. 94-1.76) for caffeine consumption. Compared with individuals who never drink coffee, the pooled OR of UI was 0.99 (95\% Cl 0.83-1.18) for regular coffee/caffeine drinkers. Coffee/caffeine consumption was not associated with moderate to severe UI (OR 1.18, $95 \% \mathrm{Cl}$ 0.88-1.58). In stratified analyses by gender, no significant association was found between $\mathrm{UI}$ risk and coffee/caffeine consumption in both men (OR 0.99, $95 \% \mathrm{Cl} 0.42-2.32$ ) and women (OR 0.92, $95 \% \mathrm{Cl}$ 0.80-1.06). By subtype, the pooled ORs were 1.01 (95\% Cl 0.86-1.19) for stress UI, $0.99(95 \% \mathrm{Cl}$ 0.84-1.16) for urge UI and 0.93 (95\% Cl 0.79-1.10) for mixed UI.
\end{abstract}

Conclusions: This meta-analysis found no evidence for an association between coffee/caffeine consumption and the risk of UI.

Keywords: Coffee, Caffeine, Urinary incontinence, Risk, Meta-analysis

\section{Background}

Urinary incontinence (UI) is a common condition with significant impact on overall health and quality of life. It has been estimated that UI prevalence ranged from 5 to $21 \%$ among community dwelling United States men [1-4]. However, UI prevalence estimates differ considerably due to the definition adopted and ranges between $10 \%$ and $40 \%$ among community-dwelling women [5-8]. Although UI is only a symptom of several conditions, ascertaining risk factors would be helpful for identifying high-risk persons and avoidable environmental causes. As for initial UI treatment, lifestyle changes such as fluid modification are strongly recommended.

\footnotetext{
* Correspondence: jiaoziyao66@sina.com

${ }^{2}$ Department of Anesthesiology, Linyi People's Hospital, Shandong 276000,

People's Republic of China

Full list of author information is available at the end of the article
}

Coffee and caffeine (coffee/caffeine) are one of the most common beverages worldwide, especially among western countries; thus, investigating its association with various diseases has important public health implications. The relationships between coffee/caffeine and risk of UI have been reported in many studies. However, present epidemiological evidence is inconsistent considering the relationships between coffee/caffeine consumption and the risk of stress, urge and mixed UI. Bortolotti et al. observed no association between coffee and risk of UI in 2000 [9]. Since then, several other studies have been published with inconclusive results [10-12]. For instance, Tettamanti reported that women who often drank coffee had a lower risk of any UI compared to women who did not drink coffee [13]. However, Davis noticed that caffeine consumption was associated with moderate to severe UI in United States men [12]. 
In order to define the possible associations between coffee/caffeine intake and the risk of UI, we performed a meta-analysis of relevant cohort, case-control and crosssectional studies.

\section{Methods}

\section{Search strategy}

In performing this meta-analysis, we abided by the Meta-Analysis of Observational Studies in Epidemiology (MOOSE) [14] and preferred reporting items for systematic reviews and meta-analyses (PRISMA) [15] guidelines. Three electronic databases (Medline, Embase and Web of Science) until July 2015 were used for systematic literature search, and search terms included coffee, caffeine, drink, beverage, risk and urinary incontinence. We did not set language or other restrictions in the literature search. As this manuscript is a meta-analysis of available studies, it does not involve ethics and require written informed consent from participants.

\section{Inclusion criteria}

The present meta-analysis only included studies which met the following inclusion criteria: (1) the exposure of interest was coffee or caffeine intake; (2) the outcome of interest was UI; (3) the study design was observational; (4) the study reported adjusted risk estimates with corresponding $95 \%$ CIs for the relationship between coffee/ caffeine consumption and risk of UI.

\section{Data extraction}

According to the guidelines for meta-analysis [14], two reviewers independently carried out eligibility evaluation and data extraction. We collected detailed information including year of publication, the name of first author, study design, age and gender of participants, number of cases, exposure, sample size and multivariate adjusted ORs and $95 \%$ CIs for each category of coffee/ caffeine intake.

\section{Statistical analysis}

It has been stated that when the outcome was rare, relative risks and ORs could provide similar estimates of risk [16]. In this present meta-analysis, ORs were adopted as a common measure of the association between coffee or caffeine intake and UI risk. In all included studies, the highest level of coffee or caffeine intake was defined as 'regularly drink coffee', and the lowest level of coffee or caffeine intake was defined as 'never drink coffee'. Notably, we only adopted the adjusted OR for this metaanalysis. We derived summary OR estimates with $95 \%$ CIs using the method of DerSimonian and Laird.

To assess heterogeneity among studies, we used the Cochran $\mathrm{Q}$ and $\mathrm{I}^{2}$ statistics. Subgroup analyses stratified by gender, extent and type of UI were also carried out to explore potential sources of heterogeneity. We evaluated publication bias using a funnel plot and the test proposed by the Begg's adjusted rank correlation test and by the Egger's regression test [17, 18]. We carried out statistical analyses using STATA, version 11.0 (STATA, College Station, TX, USA). A $p$ value of less than 0.05 was considered statistically significant.

\section{Results}

\section{Identification of studies}

The workflow of the study review is summarized in Fig. 1. A total of 259 studies were retrieved from the initial literature search (61 from the Medline, 167 from the EMBASE, and 31 from the Web of Science). After excluding 249 studies based on title and abstract reading, we reviewed the full texts of the remaining 10 potentially pertinent articles. Finally, seven studies $[9-13,19,20]$ which stated the relationship between coffee/caffeine intake and risk UI were included in our meta-analysis. The characteristics of the included studies are shown in Table 1. Among the seven included studies, three reported the data of coffee consumption and four reported caffeine consumption.

\section{Coffee/caffeine consumption and UI risk}

The results combining the ORs for the risk of UI associated with coffee/caffeine consumption was summarized in Fig. 2. The summary OR for any versus non-consumption were 0.75 (95 \% CI 0.54-1.04) for coffee and 1.29 (95\% CI 0.94-1.76) for caffeine consumption. When combining coffee and caffeine, the summary OR was 0.99 (95\% CI 0.85-1.16) with statistically significant heterogeneity among studies $\left(I^{2}=89.1 \%, p=0.000\right)$. Additionally,

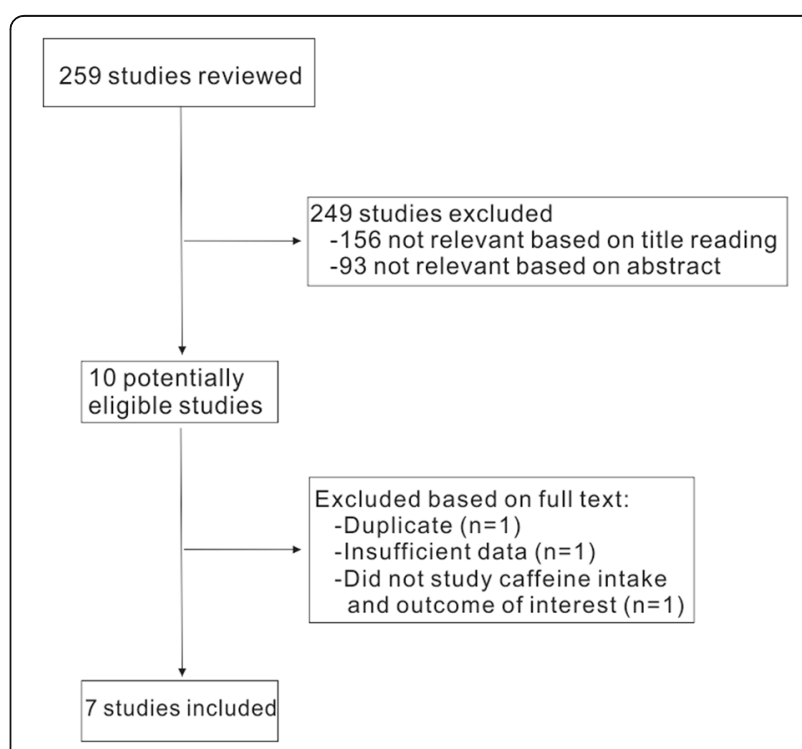

Fig. 1 Flowchart of selection of studies for inclusion in the metaanalysis on coffee/caffeine consumption and UI risk 
Table 1 Main characteristics of included studies

\begin{tabular}{|c|c|c|c|c|c|c|c|c|}
\hline First author, year & Country & Study design & Age & Gender & $\begin{array}{l}\text { Number } \\
\text { of cases }\end{array}$ & $\begin{array}{l}\text { Number of } \\
\text { participants }\end{array}$ & Exposure & Adjustments \\
\hline Bortolotti, 2000 & Italy & Cross-sectional & $\begin{array}{l}\geq 50(\mathrm{M}) \\
\geq 40(\mathrm{~F})\end{array}$ & Both & 408 & $2721(\mathrm{M}) / 2767(\mathrm{~F})$ & Coffee & Age \\
\hline Hannestad, 2003 & Norway & Cross-sectional & $\geq 20$ & Female & 6876 & 27,936 & Coffee & Age, BMI and smoking \\
\hline Jura, 2011 & USA & Cohort & 37 to 79 & Female & 15,683 & 65,176 & Caffeine & $\begin{array}{l}\text { Age, cohort, parity, BMI, cigarette } \\
\text { smoking, race, diabetes, total fluid } \\
\text { intake and physical activity }\end{array}$ \\
\hline Tettamanti, 2011 & Sweden & Cohort & 19 to 47 & Female & / & 14,094 & Coffee & $\begin{array}{l}\text { Age, parity, BMI, smoking and } \\
\text { educational level }\end{array}$ \\
\hline Hirayama, 2012 & Japan & Case-control & 40 to 75 & Both & 131 & $683(\mathrm{M}) / 298(\mathrm{~F})$ & caffeine & $\begin{array}{l}\text { Age, BMI, smoking status, alcohol } \\
\text { drinking, physical activity level, total } \\
\text { fluid intake and presence of } \\
\text { co-morbidity }\end{array}$ \\
\hline Gleason, 2013 & USA & Cross-sectional & $\geq 20$ & Female & 1767 & 4309 & Caffeine & $\begin{array}{l}\text { Age, race/ethnicity, poverty income } \\
\text { ratio, BMI, self-rated health status, } \\
\text { major depression, chronic diseases, } \\
\text { alcohol use, water intake, total dietary } \\
\text { moisture intake and reproductive } \\
\text { factors in women including vaginal } \\
\text { deliveries }\end{array}$ \\
\hline Davis, 2013 & USA & Cross-sectional & $\geq 20$ & Male & 511 & 3960 & Caffeine & $\begin{array}{l}\text { Age, race/ethnicity, education, BMI, } \\
\text { vigorous activity, poverty-to income } \\
\text { ratio, chronic disease, health status, } \\
\text { depression, alcohol intake, water } \\
\text { intake and total moisture intake }\end{array}$ \\
\hline
\end{tabular}

compared with individuals who never drink coffee, the pooled OR of UI was 0.99 (95\% CI 0.83-1.18) for regular coffee/caffeine drinkers (Fig. 3).

\section{Coffee /caffeine consumption and incidence of moderate/ severe UI}

Three studies provided results on risk of moderate/ severe UI [10, 12, 20], and one study reported the risk of frequent UI among women with daily caffeine intakes [11]. In this subgroup meta-analysis, frequent
UI was also regarded as moderate/severe UI. The summary OR was 1.18 (95\% CI 0.88 to 1.58 ) with statistically significant heterogeneity among studies $\left(I^{2}=86.9 \%, p=0.000\right)$ (Fig. 4).

Coffee /caffeine consumption and incidence of $\mathrm{UI}$ by sex Two articles reported data on risk of UI specific for gender $[9,19]$; one article consisted entirely of men [12] and four articles consisted entirely of women [10, 11, 13, 20]. In stratified analyses by gender, we did not observe any

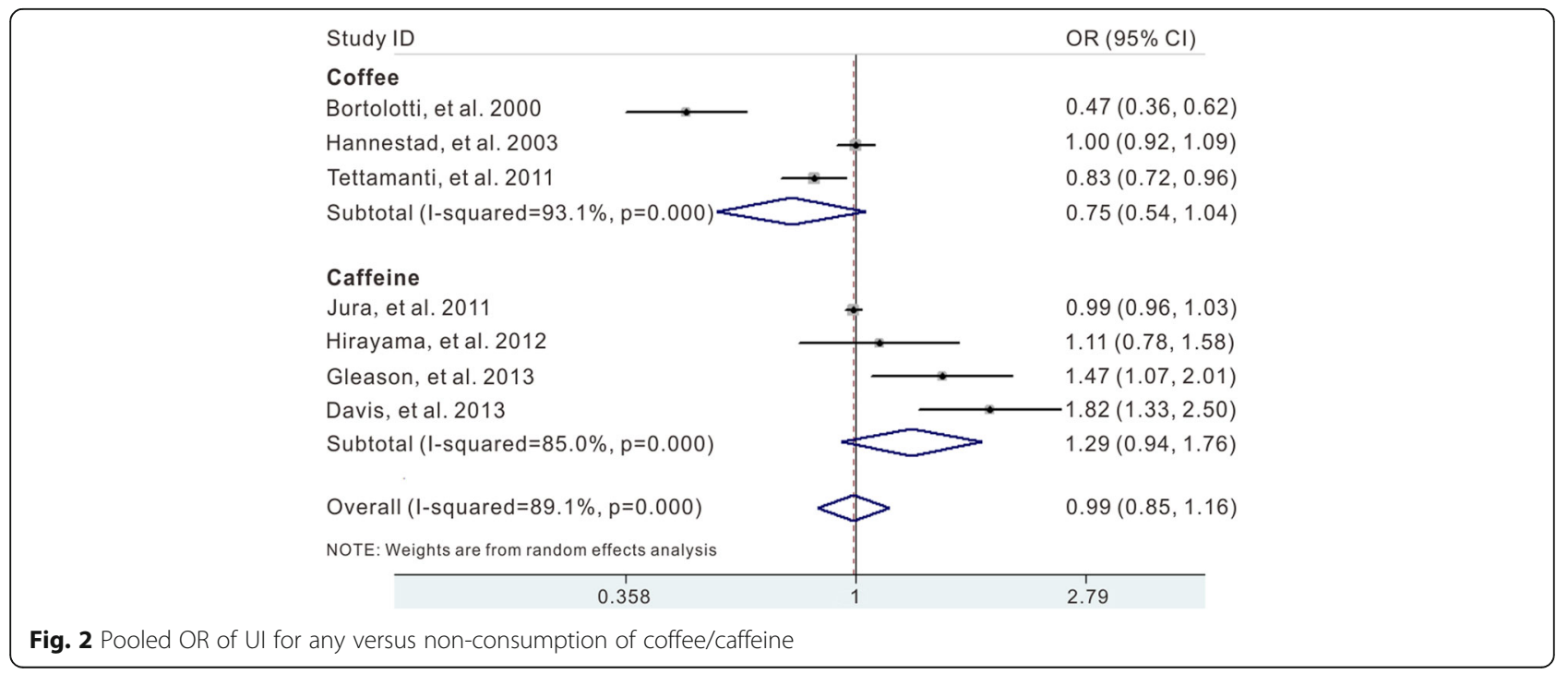




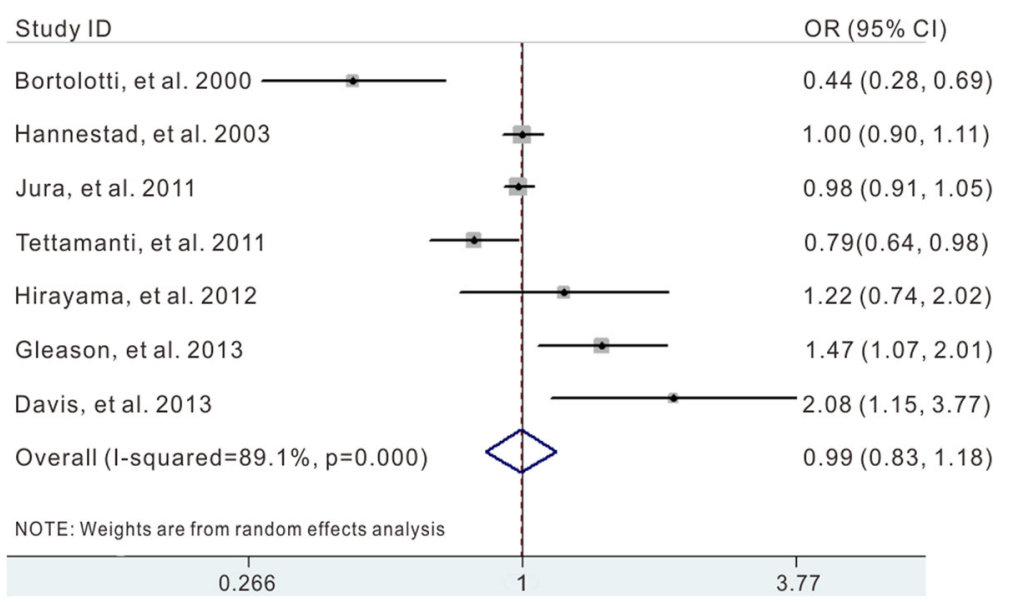

Fig. 3 Pooled OR of UI for regular versus non-consumption of coffee/caffeine

association between coffee/caffeine intake and risk of UI in both men (summary ORs, $0.99 ; 95 \% \mathrm{CI}, 0.42-2.32$ ) and women (summary ORs, 0.92; 95 \% CI, 0.80-1.06) (Fig. 5).

\section{Coffee /caffeine consumption and risk of Ul by subtype} For stress UI, the combined OR was 1.01 (95 \% CI 0.86-1.19) (Fig. 6). For urge UI, the summary OR was 0.99 (95\% CI 0.84-1.16). For mixed UI, the pooled OR was 0.93 (95\% CI 0.79 to 1.10 ). For the different subtypes of incontinence, we did not observe significant association between coffee/caffeine intake and risk of UI.

\section{Sensitivity analysis}

As for sensitivity analysis, we removed one study at a time and analyzed the rest. After excluding the study which carried the most weight [11], the OR was 1.01 (95\% CI 0.77-1.32). After excluding the study which carried the least weight [19], the OR was 0.98 (95\% CI 0.83-1.16).

\section{Publication bias}

No funnel plot asymmetry was observed for the relationship between coffee/caffeine and UI. $P$ values for Egger's regression asymmetry test was 0.998 and the Begg's adjusted rank correlation test was 0.764 , indicating a low probability of publication bias (Fig. 7).

\section{Discussion}

To our knowledge, this is the first meta-analysis to explore the association between coffee/caffeine intake and UI. We observed that coffee/caffeine consumption was not significantly associated with risk of overall UI. After deleting one study at a time and analyzing the rest, the summary OR ranged from 1.01 (95\% CI $0.77-1.32$ ) to 0.98 (95\% CI $0.83-1.16$ ). When evaluating the severity of UI symptoms, we found no relationship between coffee/caffeine consumption and moderate/severe UI. Moreover, coffee/caffeine consumption was not associated with types of UI (stress, urge, and mixed UI) when controlling for other UI risk factors.

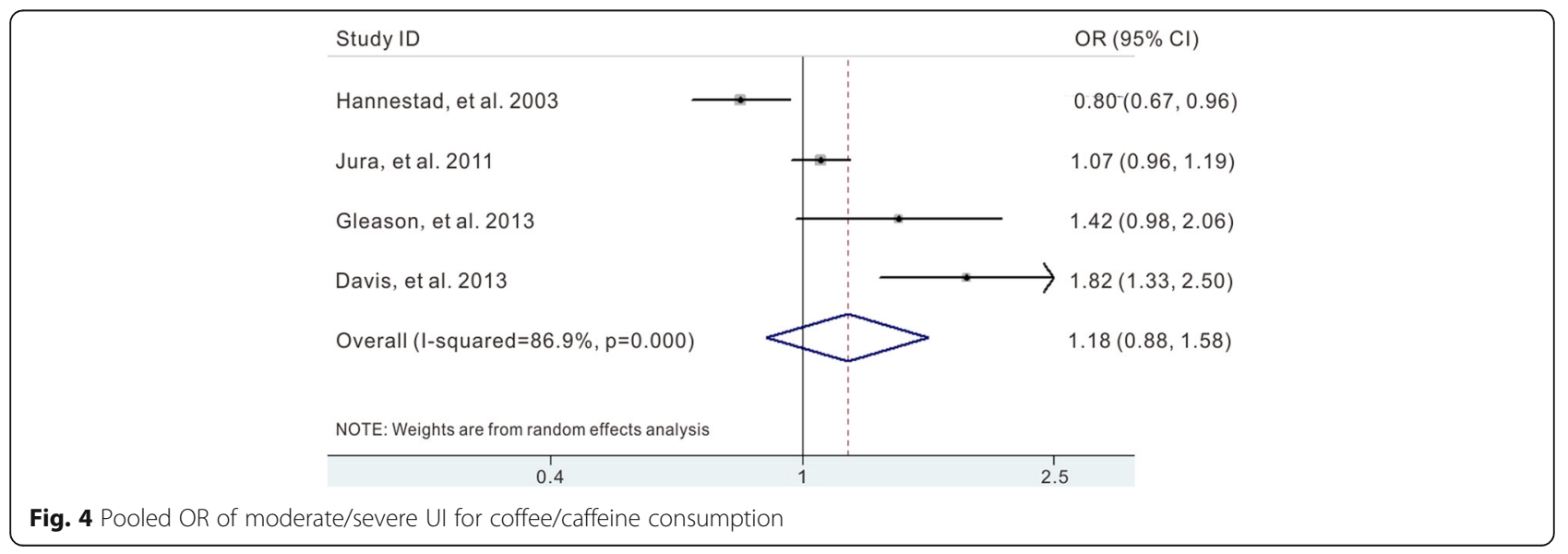




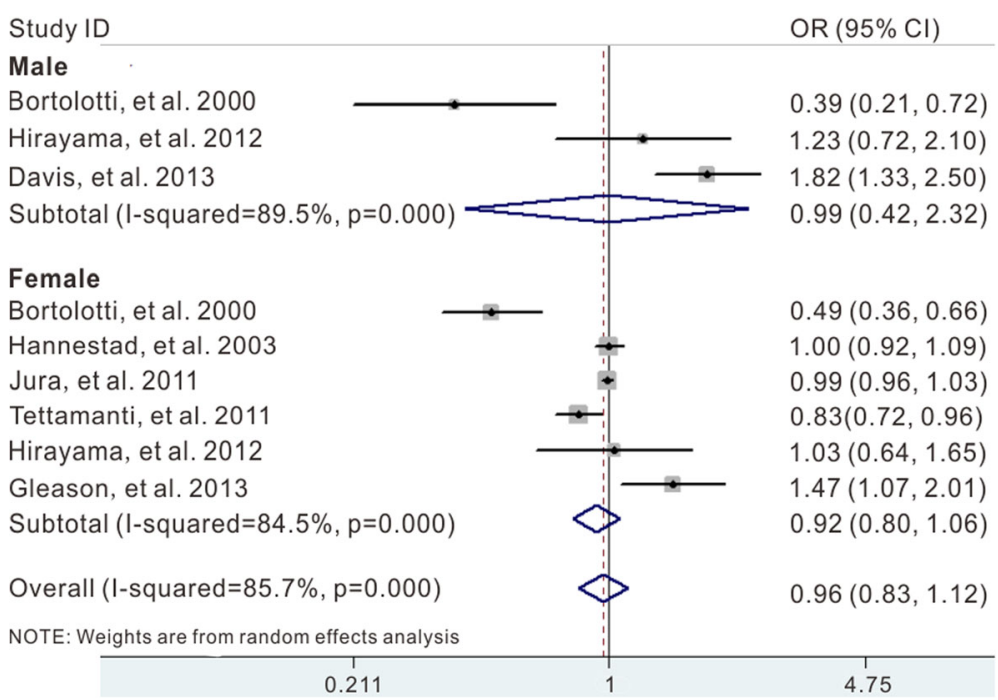

Fig. 5 Forest plots of UI risk by gender associated with coffee/caffeine consumption

Creighton and Stanton observed a statistically significant increase in detrusor pressure on bladder filling following administration of caffeine in women with detrusor instability [21]. Tomlinson et al. reported that the relationship between a decrease in the amount of dietary caffeine consumed and fewer daytime episodes of involuntary urine loss approached significance [22]. Thus, the relationship between lower urinary tract dysfunction and coffee/caffeine intake might be plausible. Considering that coffee/caffeine may exacerbate urinary incontinence, physicians often recommend a reduction in coffee/caffeine intake for individuals with incontinence symptoms.

To ascertain the impact of cumulative dose of coffee/ caffeine intake on the risk of UI, we used a meta-analytic approach to estimate overall OR and $95 \%$ CIs for regular coffee/caffeine drinkers versus individuals who seldom drank coffee/caffeine. In the seven studies, the lowest level of coffee/caffeine intake was defined as 'never drink coffee', whereas the highest level of coffee/ caffeine intake was defined as 'regularly drink coffee'. Of note, regular coffee/caffeine drinkers experienced an

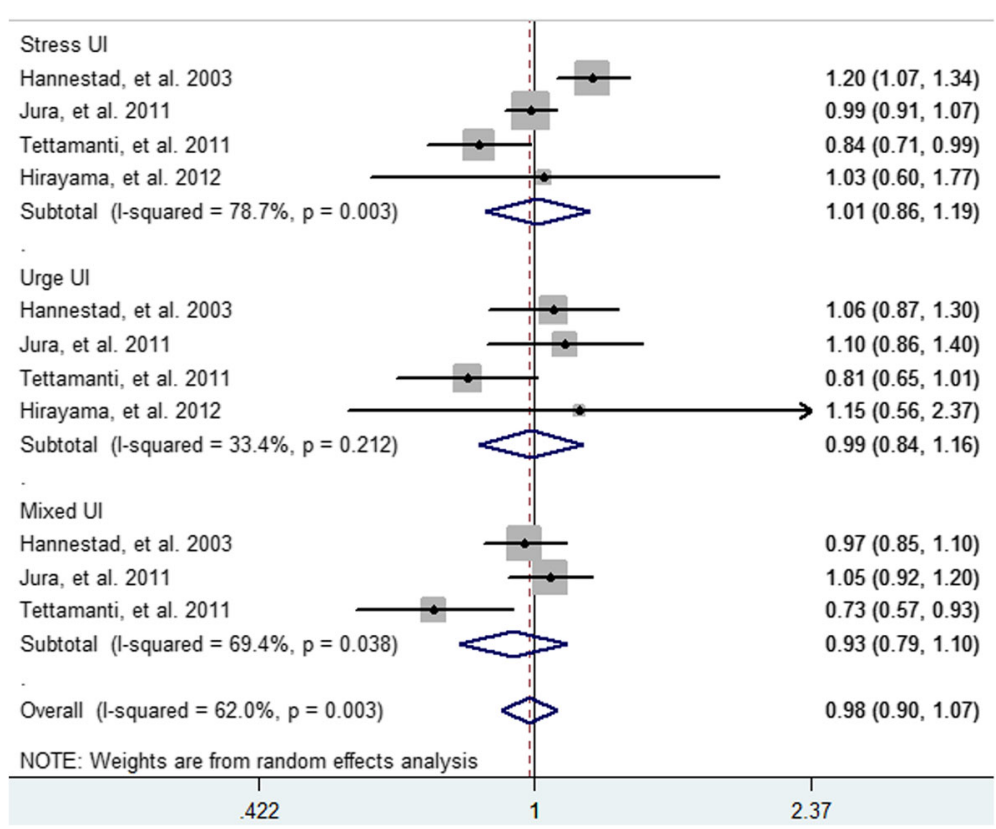

Fig. 6 Forest plots of UI risk by subtype associated with coffee/caffeine consumption 


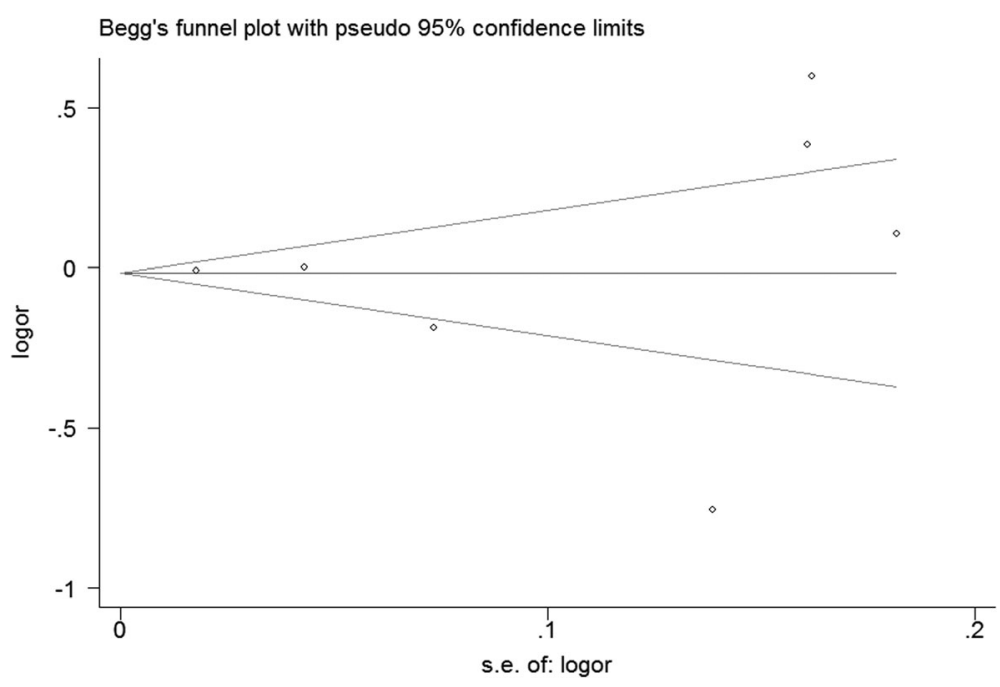

Fig. 7 Funnel plot for studies of coffee/caffeine consumption in relation to UI risk

increased risk of $18 \%$ for UI. However, no significant difference was found between the two groups.

According to the Incontinence Severity Index or other items, UI was categorized as "any" or "moderate/ severe". Three studies provided results on risk of moderate/severe UI $[10,11,20]$, and one study reported the risk of frequent UI among women with daily caffeine intakes [12]. Jura stated that frequent incontinence was UI at least once per week among incident cases. Thus, frequent UI was also regarded as moderate/severe UI in the subgroup meta-analysis.

We also explored the association between coffee/ caffeine consumption and incidence of UI by gender. Tettamanti and colleagues reported that women with a high coffee intake were at lower risk of any urinary incontinence compared with women not drinking coffee [13]. Gleason et al. found that caffeine intake $\geq$ $204 \mathrm{mg} /$ day was associated with any UI in United States women [20]. A case-control study of Japanese adults failed to find an association between coffee/caffeine intake and incidence of UI [19]. Davis et al. demonstrated that caffeine consumption was significantly associated with moderate to severe urinary incontinence in United States men [12]. However, in stratified analyses by gender, no significant association was found between coffee/caffeine consumption and UI risk in both men and women.

We also analyzed type of incontinence as outcome. Four studies provided results on risk of UI specific for type (stress, urge, and mixed UI). To the best of our knowledge, the present study is the first meta-analysis that summarized the association between coffee consumption and risk of UI by type. Hannestad and colleagues stated that coffee intake was associated with an increased risk of stress UI [10]. However, we did not observe any significant (positive or negative) relations with UI subtypes in our study.

There are several strengths in the present metaanalysis. First of all, when different ORs were provided according to the different levels of coffee/caffeine consumption, we could combine the results of subgroups and calculated a common OR. Secondly, through visual inspection of a funnel plot and Begg's and Egger's tests, we observed no evidence of publication bias. Moreover, our findings were robust and reliable based on the consistent results from sensitivity analysis.

Some limitations in our study should be of concern. Firstly, adjusted confounding factors varied among different studies. Several potential confounding factors such as parity, BMI, smoking and water intake were not considered in several articles. Secondly, although no significant evidence of publication bias was observed, publication bias might be inevitable due to unpublished studies or original data. Thirdly, categories of coffee/caffeine intake varied from articles, which might lead to significant heterogeneity. Fourthly, due to the lack of relevant studies, crucial influences of coffee/caffeine consumption, including duration of coffee/caffeine intake and type of coffee/caffeine, had not been studied enough. Furthermore, a dose-response analysis could not be carried out due to the limited data provided by the included studies.

\section{Conclusion}

In summary, to our knowledge, this is the first metaanalysis to date on the association between coffee/caffeine intake and risk of UI. The results from this meta-analysis of observational studies demonstrated that coffee/caffeine consumption was not associated with overall UI risk. Nevertheless, because of the 
potential limitations of this meta-analysis, conclusions must be drawn with caution, and more well-designed studies with large sample sizes should be conducted for further validation.

\section{Acknowledgements}

None.

\section{Funding}

No funding was obtained for this study.

\section{Availability of data and materials}

The data and meterials can be obtained by contacting the corresponding author.

\section{Authors' contributions}

Systematic review and meta-analysis SY S. Identification of studies, critical evaluation and discussion DB L and JZ Y. All authors read and approved the final manuscript.

\section{Competing interest}

The authors declare that they have no competing interests.

\section{Consent for publication}

Not applicable.

\section{Ethics approval and consent to participate}

All analyses were based on previous published studies, thus no ethical approval and patient consent are required.

\section{Author details}

'Department of General surgery, Linyi People's Hospital, Shandong 276000 People's Republic of China. 'Department of Anesthesiology, Linyi People's Hospital, Shandong 276000, People's Republic of China.

\section{Received: 29 April 2016 Accepted: 23 September 2016}

\section{Published online: 06 October 2016}

\section{References}

1. Markland AD, Richter HE, Fwu CW, et al. Prevalence and trends of urinary incontinence in adults in the United States, 2001 to 2008. J Urol. 2011;186: 589-93.

2. Abrams $P$, Andersson KE, Birder $L$, et al. Fourth International Consultation on Incontinence Recommendations of the International Scientific Committee: Evaluation and treatment of urinary incontinence, pelvic organ prolapse, and fecal incontinence. Neurourol Urodyn. 2010;29:213-40.

3. Landefeld CS, Bowers BJ, Feld AD, et al. National Institutes of Health stateof-the-science conference statement: prevention of fecal and urinary incontinence in adults. Ann Intern Med. 2008;148:449-58.

4. Anger JT, Saigal CS, Stothers $L$, et al. The prevalence of urinary incontinence among community dwelling men: results from the National Health and Nutrition Examination survey. J Urol. 2006;176:2103-8. discussion 2108.

5. Coyne KS, Sexton CC, Thompson CL, et al. The prevalence of lower urinary tract symptoms (LUTS) in the USA, the UK and Sweden: results from the Epidemiology of LUTS (EpiLUTS) study. BJU Int. 2009;104:352-60.

6. Nygaard I, Barber MD, Burgio KL, et al. Prevalence of symptomatic pelvic floor disorders in US women. JAMA. 2008;300:1311-6.

7. Tennstedt SL, Link CL, Steers WD, McKinlay JB. Prevalence of and risk factors for urine leakage in a racially and ethnically diverse population of adults: the Boston Area Community Health (BACH) Survey. Am J Epidemiol. 2008; 167:390-9.

8. Hunskaar S, Burgio K, Diokno A, et al. Epidemiology and natural history of urinary incontinence in women. Urology. 2003;62:16-23.

9. Bortolotti A, Bernardini B, Colli E, et al. Prevalence and risk factors for urinary incontinence in Italy. Eur Urol. 2000;37:30-5.

10. Hannestad YS, Rortveit G, Daltveit AK, Hunskaar S. Are smoking and other lifestyle factors associated with female urinary incontinence? The Norwegian EPINCONT Study. BJOG. 2003;110:247-54.

11. Jura YH, Townsend MK, Curhan GC, et al. Caffeine intake, and the risk of stress, urgency and mixed urinary incontinence. J Urol. 2011;185:1775-80.
12. Davis NJ, Vaughan CP, Johnson 2nd TM, et al. Caffeine intake and its association with urinary incontinence in United States men: results from National Health and Nutrition Examination Surveys 2005-2006 and 20072008. J Urol. 2013:189:2170-4.

13. Tettamanti $\mathrm{G}$, Altman D, Pedersen NL, et al. Effects of coffee and tea consumption on urinary incontinence in female twins. BJOG. 2011;118:806-13.

14. Stroup DF, Berlin JA, Morton SC, et al. Meta-analysis of observational studies in epidemiology: a proposal for reporting. Meta-analysis Of Observational Studies in Epidemiology (MOOSE) group. JAMA. 2000:283:2008-12.

15. Moher D, Liberati A, Tetzlaff J, Altman DG. Preferred reporting items for systematic reviews and meta-analyses: the PRISMA statement. J Clin Epidemiol. 2009;62:1006-12.

16. Greenland S. Quantitative methods in the review of epidemiologic literature. Epidemiol Rev. 1987;9:1-30.

17. Begg CB, Mazumdar M. Operating characteristics of a rank correlation test for publication bias. Biometrics. 1994;50:1088-101.

18. Egger M, Davey SG, Schneider M, Minder C. Bias in meta-analysis detected by a simple, graphical test. BMJ. 1997;315:629-34.

19. Hirayama F, Lee AH. Is caffeine intake associated with urinary incontinence in Japanese adults. J Prev Med Public Health. 2012:45:204-8.

20. Gleason JL, Richter HE, Redden DT, et al. Caffeine and urinary incontinence in US women. Int Urogynecol J. 2013:24:295-302.

21. Creighton SM, Stanton SL. Caffeine: does it affect your bladder. Br J Urol. 1990;66:613-4.

22. Tomlinson BU, Dougherty MC, Pendergast JF, et al. Dietary caffeine, fluid intake and urinary incontinence in older rural women. Int Urogynecol J Pelvic Floor Dysfunct. 1999;10:22-8.
Submit your next manuscript to BioMed Central and we will help you at every step:

- We accept pre-submission inquiries

- Our selector tool helps you to find the most relevant journal

- We provide round the clock customer support

- Convenient online submission

- Thorough peer review

- Inclusion in PubMed and all major indexing services

- Maximum visibility for your research

Submit your manuscript at www.biomedcentral.com/submit 